\title{
FURTHER STUDIES ON THE DISTENSIBILITY OF THE EYE*
}

BY

\author{
E. S. PERKINS AND J. GLOSTER \\ Institute of Ophthalmology, University of London
}

IN a previous paper we have shown that the so-called coefficient of ocular rigidity $K$ is not constant for the rabbit eye, but increases with intra-ocular pressure up to approximately $50 \mathrm{~cm}$. saline (Perkins and Gloster, 1957). The first part of the present study concerns determinations at higher pressures and in enucleated, as opposed to living and dead eyes in situ. In the second part we have attempted to extend the investigation to more practical problems by a study of tonometry and tonometric methods for the determination of the rigidity of rabbit eyes.

\section{PART I}

Ocular Distensibility at High Pressures and in EnuCleated Rabbit Eyes

The results given in our previous paper were obtained from living and dead eyes in situ and we were interested to know whether similar results would be obtained in an enucleated eye, unsupported by the orbital tissues.

The manometric method previously described in full (Perkins and Gloster, 1957) was used on one eye, and the results were found to follow closely those obtained from eyes still in the orbit.

In a second enucleated eye, the technique was modified in that, instead of

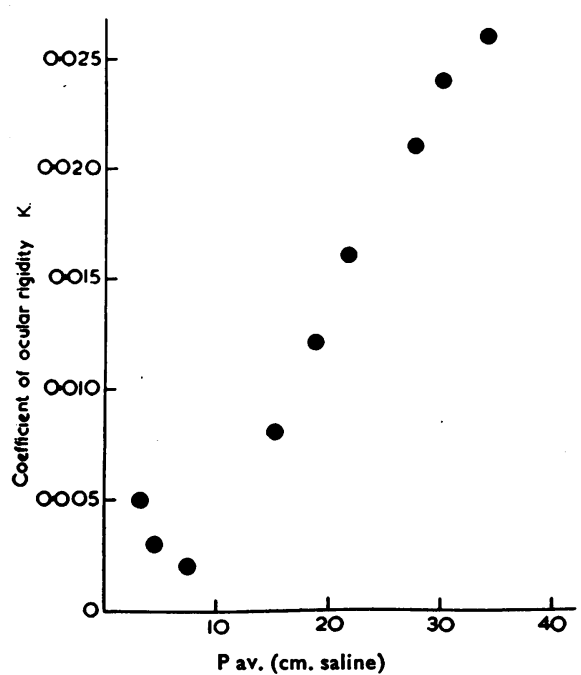

Fig. 1.-Variation of coefficient of ocular rigidity with intra-ocular pressure. Optic nerve cannulation. Rabbit eye.

$\left(\boldsymbol{P}_{a v}=\right.$ mean of intra-ocular pressures before and after injecting saline.) using a needle in the anterior chamber, a glass cannula was introduced into the vitreous cavity through the optic nervehead and tied into place. The manometer was connected to this cannula and the injections of saline into the eye were also made through the cannula. The eye was supported by immersion in a beaker of saline at room temperature. This method was employed to conform more closely to the experimental conditions of other workers (Schultén, 1884; Ridley, 1930) and to determine whether our previous results had been influenced by the slight corneal deformation caused by insertion of a needle into the anterior chamber. Again, as shown in Fig. 1, the results conform to those obtained by the original method. 
Our earlier results suggested that the value of $K$ probably reached a maximum at intra-ocular pressures of $50-60 \mathrm{~cm}$. saline, and in order to study the ocular distensibility at higher pressures the thin rubber membrane of the manometer was replaced by thicker rubber. By this means pressures up to $150 \mathrm{~cm}$. saline could be employed.

Fig. 2 shows the results of such an experiment on a rabbit anaesthetized with urethane $1.75 \mathrm{~g}$. $/ \mathrm{kg}$., and after killing the animal. The values of $K$ in both the living and dead eye decreased slightly between 60 and $100 \mathrm{~cm}$. saline. Above this pressure, $K$ for the dead eye continued to decrease, but in the living eye $K$ tended to increase slightly. All values for $K$ in the dead eye were higher than in the living eye. The results in a second rabbit were very similar.

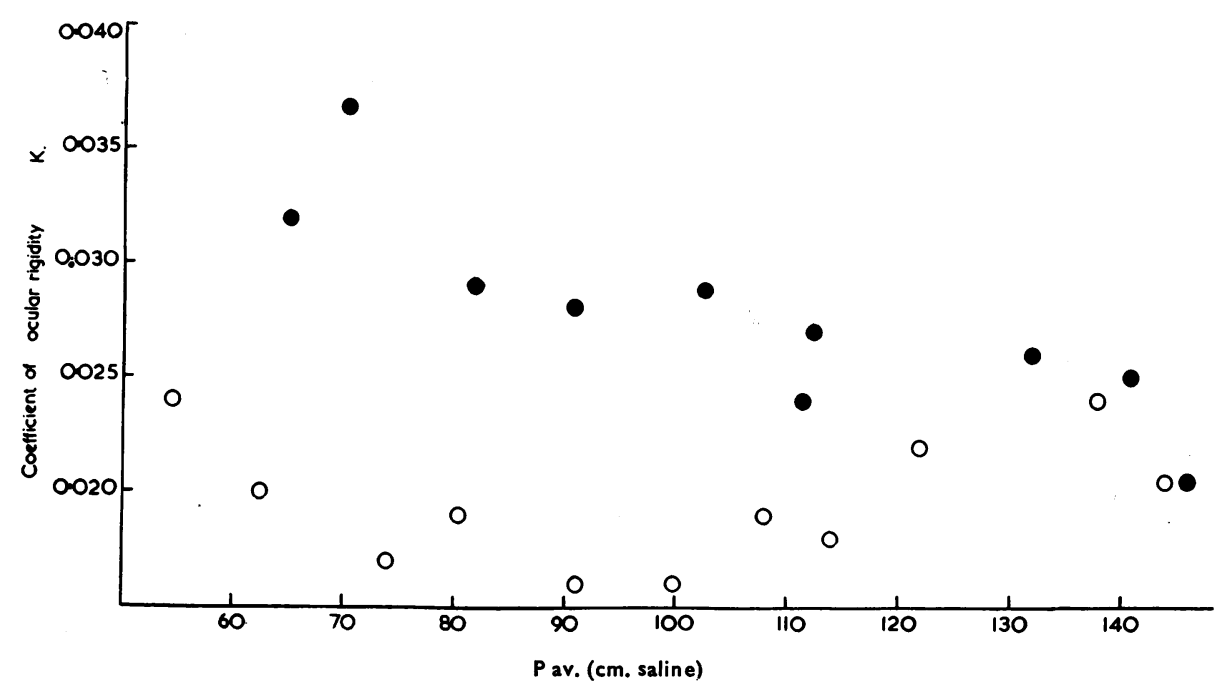

FIG. 2.-Variation of coefficient of ocular rigidity with intra-ocular pressures above $50 \mathrm{~cm}$. Saline. Rabbit eye.

$$
\text { ○ living eye. } \quad \text { dead eye. }
$$

\section{Discussion}

The practical conclusion which can be drawn from these results is that determinations of rigidity on enucleated rabbit eyes give comparable results to those obtained with the dead eye in situ. The fact that there was little difference in the relationship between $K$ and intra-ocular pressure, when determinations were made with a needle in the anterior chamber or by means of a cannula through the optic nerve, is confirmatory evidence that this relationship is due to certain properties of the eye and not merely a reflection of distortions of its shape.

The behaviour of $K$ at high pressures is only of theoretical interest at the moment. It is perhaps worth noticing, however, that the tendency for $K$ 
to show less variation at these pressures might be expected from the behaviour of isolated strips of sclera when subjected to increase in tension (Gloster, Perkins, and Pommier, 1957). In this paper it was shown that, at tensions corresponding to these higher pressures, the elongation of the strip was nearly proportional to the increase in tension.

\section{PART II}

\section{TONOMETRIC DeTERMINATIONS OF OCULAR DistensibILITY}

When a tonometer is placed on an eye, the intra-ocular pressure of which is signified by $\boldsymbol{P}_{o}$, the cornea is indented, partly by the plunger and partly by the footplate of the tonometer. Although there can be no instantaneous change in volume within the eye, the coats of the eye must stretch to accommodate the fluid displaced by the indentation of the cornea. This increased tension in the coats of the eye raises the intra-ocular pressure to a higher level $P_{t}$. The height of the new level will depend on the resistance to distension of the eye, i.e. on the ocular rigidity.

The manometric and volumetric methods for determining $K$ which we have previously used have involved changing the intra-ocular volume and measuring the consequent change in pressure within the eye. It will be appreciated, therefore, that the conditions are not quite comparable to tonometry, in which the pressure within the eye is increased by deformation without a change in intra-ocular volume. Indeed some confusion exists in the literature, and Friedenwald (1937) and again Friedenwald and Moses (1950) considered that the rigidity coefficient applicable to tonometry might have a value about ten times greater than that obtained by distension of the eye. However, as the result of experiments carried out by Grant, Friedenwald (1954) concluded that "the coefficient of rigidity for ocular distension is equal to that for ocular distortion under the tonometric load". In view of our finding, using methods involving ocular distension, that $K$ was not constant for the rabbit eye, it seemed necessary to extend our studies to include tonometric determinations of ocular rigidity.

Theoretically there are two ways in which a tonometer may be used to measure rigidity. If the pressure in the eye is $P_{o}$ before, and $P_{t}$ after the tonometer has been applied, $K=\frac{\log P_{t}-\log P_{o}}{V_{c}}$, where $V_{c}$ is the volume of corneal indentation. In the second method, an extra weight is added to the tonometer and the relationship here is

$$
K=\frac{\log P_{t_{2}}-\log P_{t_{1}}}{V_{c_{2}}-V_{c_{1}}},
$$

where $P_{t_{1}}$ is the pressure in the eye with the tonometer alone, $P_{t_{2}}$ is the pressure after the addition of a weight, and $V_{c_{1}}$ and $V_{c_{2}}$ are the volumes of corneal indentation corresponding to $P_{t_{1}}$ and $P_{t_{2}}$. 
In practice, this means that it is necessary to convert the scale readings of the tonometer into pressures and volumes of corneal indentation. The usual clinical estimation of rigidity is based on the second of these two methods and will be described first.

\section{Method 1. Tonometry with Two Weights}

Rabbits weighing 2.3 and $4 \mathrm{~kg}$. were anaesthetized with $1.75 \mathrm{~g} . / \mathrm{kg}$. urethane injected intravenously. The head was fixed with one eye uppermost and sutures inserted into the lids to expose the cornea.

A standardized weighted Schiøtz tonometer was held vertically above the eye in a clamp which could be raised and lowered mechanically. The tonometer was lowered on to the eye and the scale reading noted, and the tonometer was then raised from the eye as soon as possible. Tonometry was then repeated, using the 7.5 and 10 -g. weights. In other determinations the initial reading was taken with the 7.5-g. weight: this was removed and the second reading taken with the 10-g. weight.

An 18-gauge needle was now inserted into the anterior chamber and connected by means of rigid polythene tubing and a 3-way tap $T$ to a calibrated capillary tube which was in turn connected to a reservoir of saline $\mathbf{R}$ (Fig. 3). The tap was kept open throughout the experiment, connecting the eye, capillary tube, and syringe S. A small air bubble was introduced into the capillary tube. The

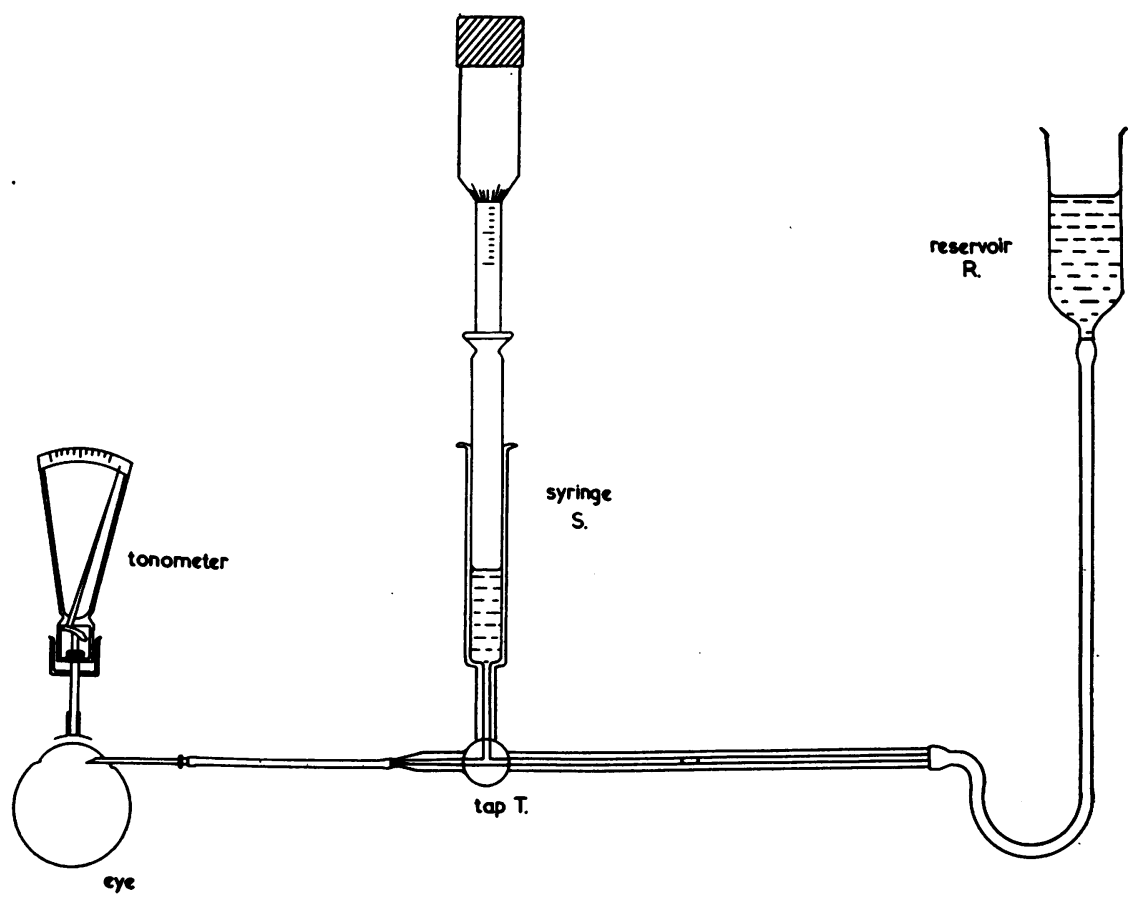

FIG. 3.-Apparatus for calibrating tonometer and determining ocular rigidity (see text). 
saline reservoir was adjusted to a height of $10 \mathrm{~cm}$. above the eye and the air bubble brought to a suitable position in the capillary tube by means of the micrometer syringe $\mathrm{S}$. The tonometer was now placed on the eye and the scale reading of the tonometer and the movement of the bubble were recorded. This procedure was then repeated at various pressure levels up to approximately $80 \mathrm{~cm}$. saline, and with $7 \cdot 5$ and $10-\mathrm{g}$. weights on the tonometer.

From these results, calibration curves of tonometer scale readings against "open stopcock" pressures in the eye and against volumes of corneal indentation were constructed for the tonometer with 5.5-g., 7·5-g., and 10-g. weights added. It was then possible to convert the scale readings obtained on the intact eye (as described above) into values for $P_{t 1}, P_{t 2}, V_{c 1}$, and $V_{c 2}$. Substitution into the formula $K=\frac{\log P_{t 2}-\log P_{t 1}}{V_{c 2}-V_{c 1}}$ gave values for $K$ shown in Table I.

TABLE I

DETERMINATION OF COEFFICIENT OF OCULAR RIGIDITY $K$ BY TONOMETRY USING TWO WEIGHTS

RABBIT EYES

\begin{tabular}{|c|c|c|c|c|c|}
\hline \multicolumn{2}{|c|}{ Rabbit 6233} & \multicolumn{2}{|c|}{ Rabbit 6263} & \multicolumn{2}{|c|}{ Rabbit 6267} \\
\hline $\begin{array}{c}\text { Pressure } \\
\text { (cm. saline) }\end{array}$ & $K$ & $\begin{array}{c}\text { Pressure } \\
\text { (cm. saline) }\end{array}$ & $K$ & $\begin{array}{c}\text { Pressure } \\
(\mathrm{cm} . \text { saline })\end{array}$ & $K$ \\
\hline 44 & 0.003 & 50 & 0.314 & 51 & $0 \cdot 121$ \\
\hline 46 & 0.008 & 52 & - & 52 & - \\
\hline 48 & 0.046 & 57 & 0.029 & 53 & $0 \cdot 107$ \\
\hline 49 & 0.008 & 60 & 0.032 & 53 & 0.036 \\
\hline 51 & 0.001 & 60 & 0.018 & 56 & 0.096 \\
\hline 51 & 0.032 & 60 & 0.044 & 56 & 0.021 \\
\hline 51 & 0.036 & 61 & 0.013 & 57 & 0.017 \\
\hline 53 & 0.048 & 63 & 0.051 & 58 & $0 \cdot 166$ \\
\hline 56 & 0.020 & 64 & 0.007 & 58 & 0.021 \\
\hline 56 & 0.038 & & & & \\
\hline 59 & 0.006 & & & & \\
\hline
\end{tabular}

In view of the wide variation in values of $K$ obtained for the same eye, this method was abandoned. The probable reasons for this failure will be discussed later.

\section{Method 2}

This method has so far been applied only to enucleated rabbit eyes.

The enucleated eye was supported in a block of paraffin wax hollowed out to fit the posterior segment of the eye. A needle was inserted into the anterior chamber and connected to a capillary tube, reservoir, and micrometer syringe as in the first method, and the tonometer was mounted above the eye as before (Fig. 3). 
The reservoir was adjusted to the required pressure and the bubble was brought to a suitable position in the capillary tube. The tap was left open and the tonometer lowered on to the eye. The scale reading $\left(R_{1}\right)$ on the tonometer and the movement of the bubble in the capillary tube were noted at this pressure. The tonometer was now raised off the eye and, after allowing time for the eye to resume its original volume, the tap $T$ was turned to isolate the eye from the rest of the system. The tonometer was immediately lowered on to the eye again and the scale reading $R_{2}$ noted. This procedure was repeated at various levels of pressure and with the $5 \cdot 5$-g., $7 \cdot 5$-g., and 10 -g. weights.

From these results, graphs were plotted relating scale readings to "open stopcock" pressures and to volumes of corneal indentation. Examples of these graphs are shown in Figs 4 and 5.

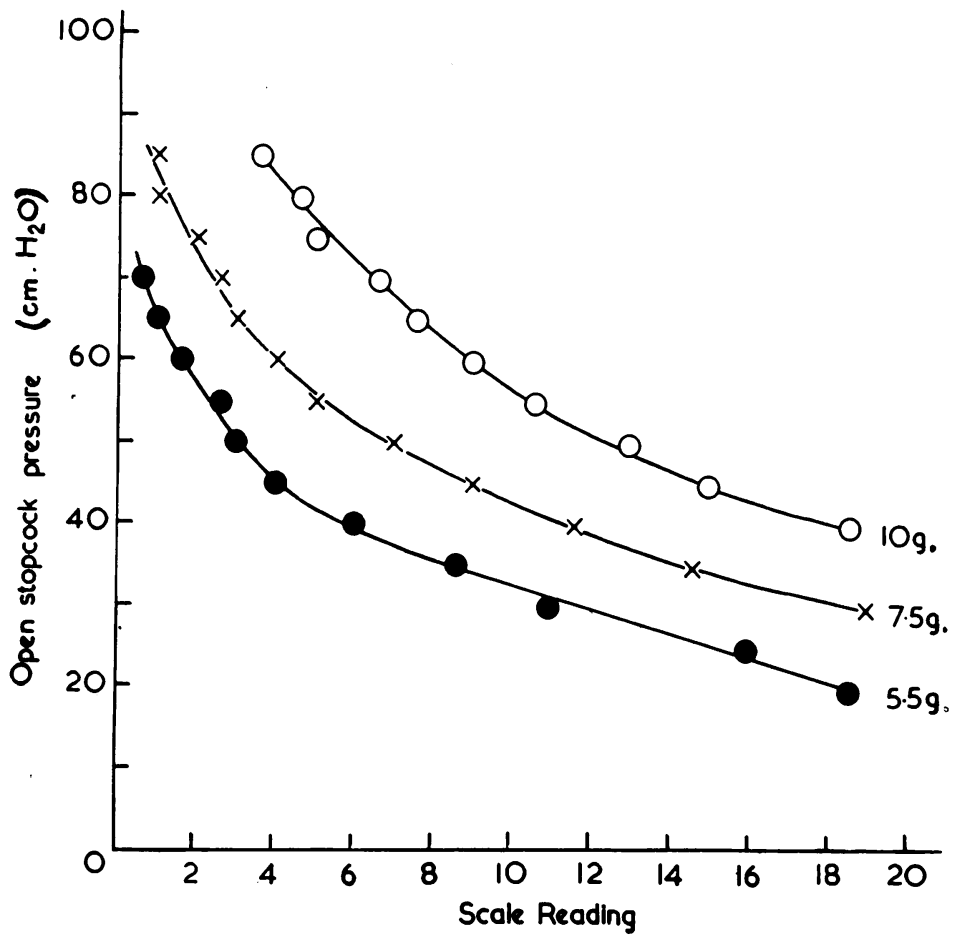

Fig. 4.-Calibration of tonometer for "open stopcock" pressures. Rabbit eye.

In the last two animals in this group, the volume of corneal indentation was obtained from a graph of the means of measurements on four other rabbit eyes. The variation from animal to animal was sufficiently small to justify this procedure.

Calculation.-The initial pressure in the eye $\left(P_{o}\right)$ was known from the height of the reservoir. The intra-ocular pressure $\left(P_{t}\right)$ with the tonometer on the eye was obtained by reading a value for $R_{2}$ from the graph of scale readings against "open stopcock" pressures. The volume of corneal indentation for $R_{2}$ could be derived from the graph of scale readings against volumes. 


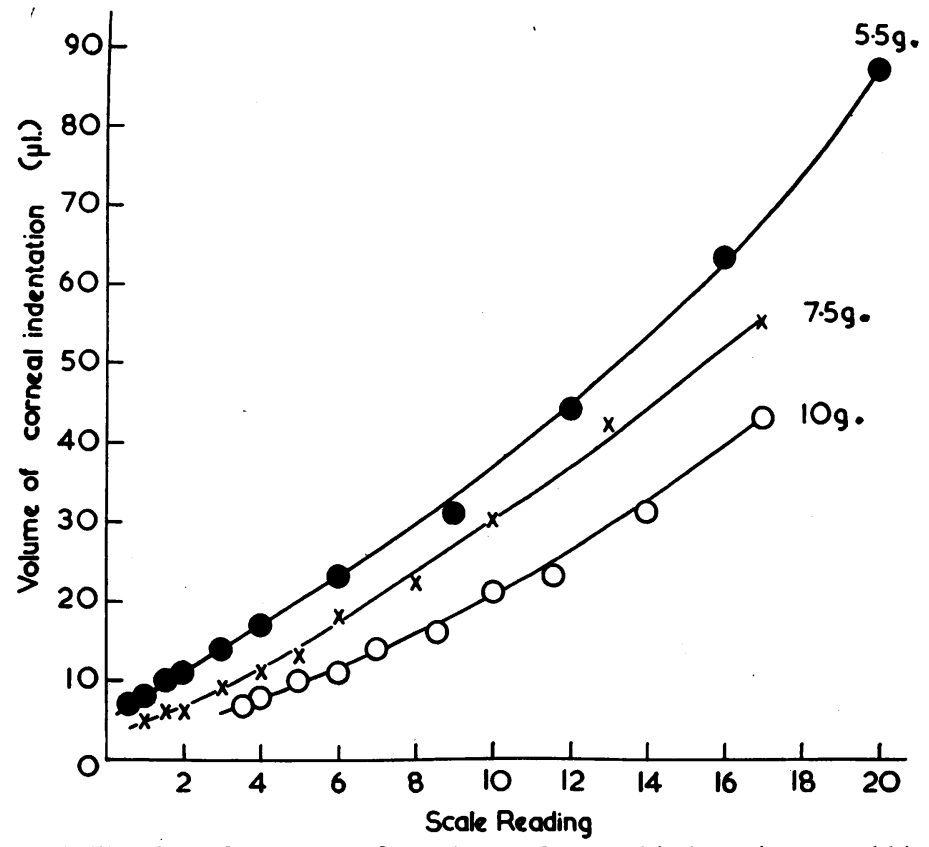

FIG. 5.-Calibration of tonometer for volume of corneal indentation. Rabbit eye.

$$
\text { Applying the formula } \quad K=\frac{\log P_{t}-\log P_{o}}{V_{c}},
$$

values for $K$ were obtained for various levels of pressure and with different weights on the tonometer. A typical result from one eye is shown in Fig. 6.

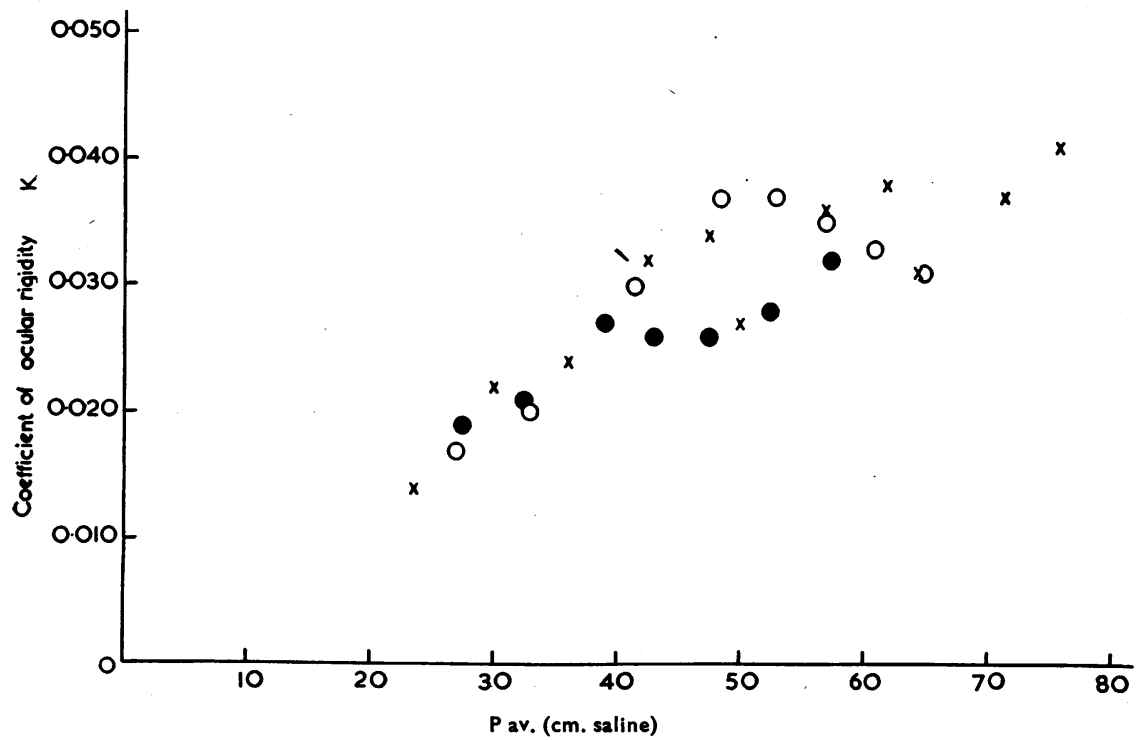

Fig. 6.-Variation of coefficient of ocular rigidity with intra-ocular pressure, using a tono31 metric method. 
It can be seen that $K$ increased as the pressure at which it was determined increased, and also that values obtained with different weights at comparable pressures did not differ markedly. The results for all four eyes are summarized in Table II, which gives mean values for $K$ in four ranges of pressure, and shows clearly that in every case $K$ increased with the intra-ocular pressure up to a level of $50 \mathrm{~cm}$. saline. Above this level the values showed less marked changes.

TABLE II

VARIATIONS OF $K$ WITH INTRA-OCULAR PRESSURE FOR FOUR RABBIT EYES TONOMETRIC DETERMINATION OF $K$

\begin{tabular}{|c|c|c|c|c|c|c|c|c|}
\hline \multirow{3}{*}{$\begin{array}{l}\text { Rabbit } \\
\text { No. }\end{array}$} & \multicolumn{8}{|c|}{ Coefficient of Ocular Rigidity $K$} \\
\hline & \multicolumn{2}{|c|}{$\begin{array}{l}\text { Pressure Range } \\
15-25 \mathrm{~cm} \text {. Saline }\end{array}$} & \multicolumn{2}{|c|}{$\begin{array}{c}\text { Pressure Range } \\
30-40 \mathrm{~cm} \text {. Saline }\end{array}$} & \multicolumn{2}{|c|}{$\begin{array}{l}\text { Pressure Range } \\
45-55 \mathrm{~cm} \text {. Saline }\end{array}$} & \multicolumn{2}{|c|}{$\begin{array}{l}\text { Pressure Range } \\
60-70 \mathrm{~cm} \text {. Saline }\end{array}$} \\
\hline & Mean & No. & Mean & No. & Mean & No. & Mean & No. \\
\hline $\begin{array}{l}1 \\
2 \\
3 \\
4\end{array}$ & $\begin{array}{l}0.014 \\
0.009 \\
0.006 \\
0.012\end{array}$ & $\begin{array}{l}1 \\
3 \\
2 \\
2\end{array}$ & $\begin{array}{l}0.023 \\
0.016 \\
0.014 \\
0.027\end{array}$ & $\begin{array}{l}5 \\
4 \\
6 \\
4\end{array}$ & $\begin{array}{l}0.032 \\
0.023 \\
0.016 \\
0.040\end{array}$ & $\begin{array}{l}7 \\
6 \\
7 \\
5\end{array}$ & $\begin{array}{l}0.033 \\
0.023 \\
0.015 \\
0.045\end{array}$ & $\begin{array}{l}4 \\
6 \\
6 \\
6\end{array}$ \\
\hline
\end{tabular}

\section{Discussion}

(1) Tonometry with Two Weights.-It is obvious from the results (Table I) that the values of $K$ obtained by this method are quite unreliable. The very large differences between consecutive determinations are quite contrary to previous experience using other methods. Considering that these experiments were done under laboratory conditions in which eye movements were eliminated and the tonometer raised and lowered mechanically, the failure of this method seems surprising. However, from the work of Rohrschneider and Küchle (1954), it is apparent that the mechanical and reading errors combined may easily amount to hálf a scale division for each application of the tonometer.

Reference to the graphs for pressure and volume (Figs 4 and 5) shows that such a variation can cause serious errors in the values obtained. For example, in one experiment the initial scale reading with the $5 \cdot 5-\mathrm{g}$. weight was recorded as 2.5 . The reading with the $7 \cdot 5$-g. weight was $5 \cdot 5$; the rigidity calculated from these readings was 0.032 . Supposing the first reading to have been 2.25 or $2 \cdot 75$, and the second to have been $5 \cdot 25$ or $5 \cdot 75$, the following results for the coefficient of rigidity would have been obtained (Table III, opposite).

It can be seen that an error of this magnitude could lead to a more than ten-fold variation in the coefficient of rigidity. The greater part of this variation can be accounted for by the variation in the changes of volume. 
TABLE III

ILLUSTRATION OF EFFECT OF TONOMETRIC READING ERRORS ON THE DETERMINATION OF THE COEFFICIENT OF OCULAR RIGIDITY

\begin{tabular}{|c|c|c|c|c|c|c|c|c|}
\hline \multirow{2}{*}{$\begin{array}{c}\text { Results } \\
\begin{array}{c}\text { Weight } \\
\text { (g.) }\end{array}\end{array}$} & \multicolumn{2}{|c|}{ Scale Readings } & \multicolumn{2}{|c|}{$\begin{array}{c}\text { Intra-Ocular } \\
\text { Pressures } \\
\text { (cm. saline) }\end{array}$} & \multicolumn{2}{|c|}{$\begin{array}{l}\text { Volume of Corneal } \\
\text { Indentation }(\mu 1 .)\end{array}$} & \multirow{2}{*}{$\begin{array}{c}V_{2}-V_{1} \\
(\mu 1 .)\end{array}$} & \multirow{2}{*}{$K$} \\
\hline & $5 \cdot 5$ & $7 \cdot 5$ & $5 \cdot 5$ & $7 \cdot 5$ & $\begin{array}{l}V_{1} \\
5 \cdot 5\end{array}$ & $\begin{array}{l}V_{2} \\
7 \cdot 5\end{array}$ & & \\
\hline Actual Readings & $2 \cdot 5$ & $5 \cdot 5$ & $56 \cdot 5$ & $63 \cdot 0$ & $10 \cdot 75$ & $12 \cdot 25$ & 1.5 & 0.032 \\
\hline \multirow{4}{*}{$\begin{array}{c}\text { Possible } \\
\text { Variations in } \\
\text { Scale Readings }\end{array}$} & $2 \cdot 25$ & $5 \cdot 25$ & $58 \cdot 0$ & $64 \cdot 0$ & 10 & 12 & 2 & 0.021 \\
\hline & $2 \cdot 25$ & $5 \cdot 75$ & $58 \cdot 0$ & $62 \cdot 0$ & 10 & 13 & 3 & 0.010 \\
\hline & $2 \cdot 75$ & $5 \cdot 25$ & $55 \cdot 0$ & $64 \cdot 0$ & $11 \cdot 5$ & 12 & 0.5 & $0 \cdot 132$ \\
\hline & $2 \cdot 75$ & $5 \cdot 75$ & 55.0 & 62.0 & $11 \cdot 5$ & 13 & 1.5 & 0.035 \\
\hline
\end{tabular}

Table II shows that the pressures at which the determinations of $K$ can be made by this method are all above $40 \mathrm{~cm}$. saline. This is inevitable because the intra-ocular pressure is always raised considerably by the act of placing a tonometer on the eye, and it must be remembered that this method of estimating the rigidity cannot give a value for $K$ at or near the normal intra-ocular pressure. This could lead to serious error if $K$ varied significantly with intra-ocular pressure-as has been shown for the rabbit eye. At the moment we have insufficient data to determine the importance of this factor in the human eye.

(2) The second tonometric method could not be applied to the intact eye but gave results which were much more consistent for the following reasons:

(a) The initial pressure in the eye $\left(P_{o}\right)$ was known from the height of the reservoir and did not depend on a tonometric reading.

(b) The volume of corneal indentation was determined from a single tonometric reading.

(c) The changes in both pressure and volume were greater than in the first method and therefore small errors in their measurement had less effect on the values of $K$.

It is clear from these results that ocular rigidity measured by tonometry, which involves some degree of distortion of the eye, does not differ significantly from ocular rigidity as measured by simple distension of the eye. This confirms Friedenwald's later views on this point (Friedenwald, 1954).

Not only were the values of $K$ substantially the same, but they showed the same variation with intra-ocular pressure. This may help to explain the recognized unreliability of tonometric determinations of intra-ocular pressure in the rabbit. This is demonstrated very clearly by a comparison of the "open" and "closed" stopcock calibrations obtained during these experiments. 
Fig. 7 shows "open stopcock" pressures plotted against scale readings for four rabbits, and it is evident that there is little scatter between the four sets of results.

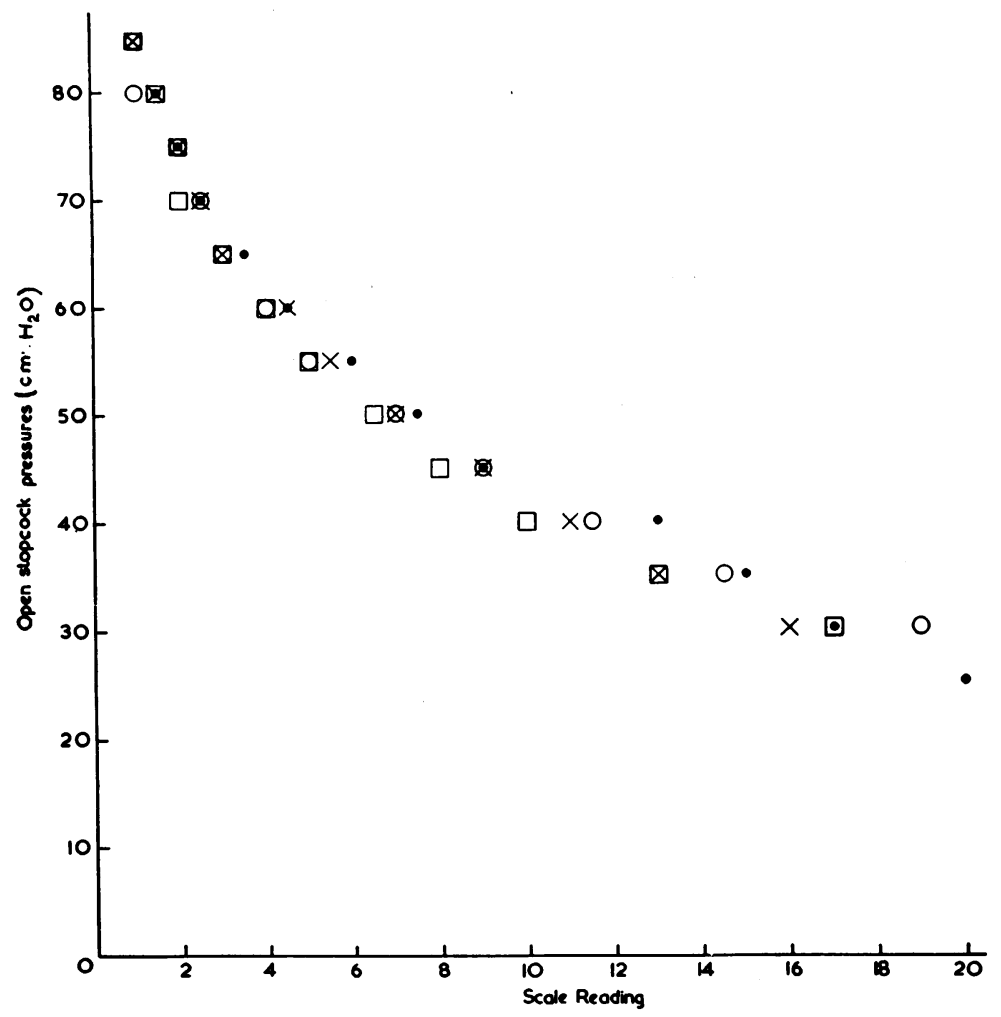

FIG. 7.-Calibration of tonometer for "open stopcock" pressures in four rabbit eyes.

Fig. 8 (opposite) shows "closed stopcock" calibrations for two of these animals and it can be seen that the same scale reading indicates widely different pressures; e.g. a scale reading of 4 corresponded to a pressure of $24 \mathrm{~cm}$. saline in one rabbit and to a pressure of $44 \mathrm{~cm}$. saline in the other. The difference between these two curves is mainly due to differences in ocular rigidity, and therefore any method of measuring the intra-ocular pressure which involves relatively large volumetric displacements must take ocular rigidity into account. As the rigidity differs from animal to animal and also varies with intra-ocular pressure, it is impossible to formulate a calibration for an instrument such as a Schiøtz tonometer which will compensate for such variations in rigidity with any degree of reliability.

One solution of this problem is to employ a method in which volumetric displacements by the tonometer are kept to a minimum. Such conditions can be obtained by the use of applanation tonometry. This advantage has 


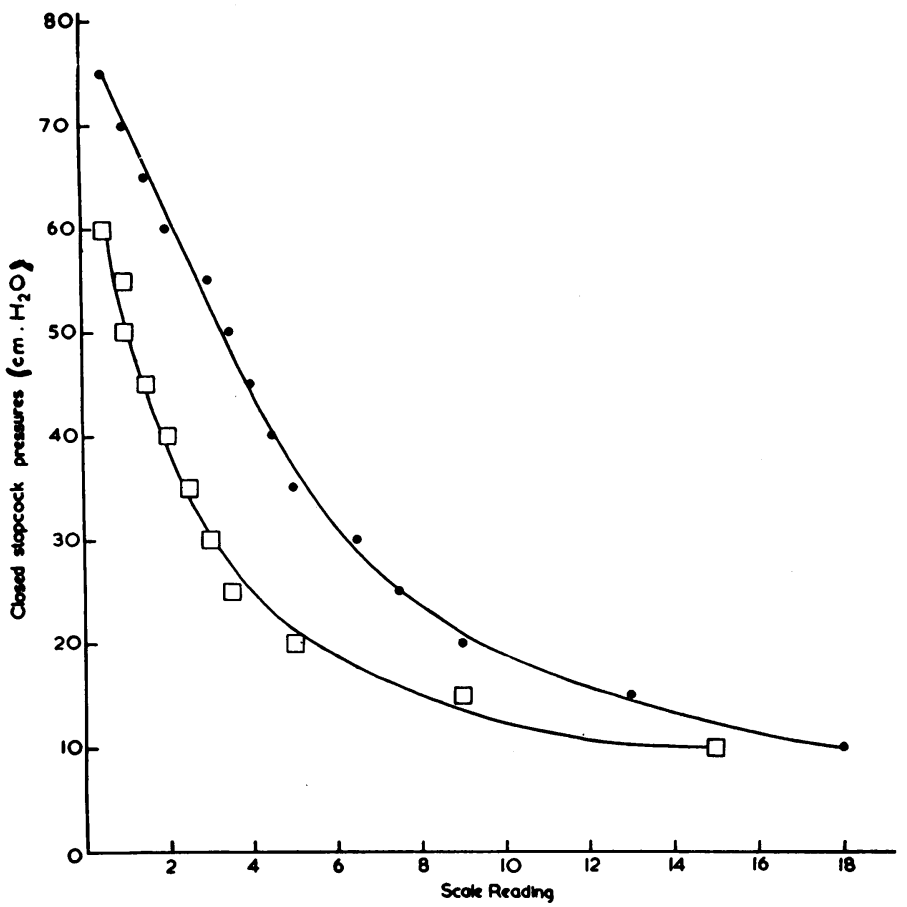

FiG. 8.-Calibration of tonometer for "closed stopcock" pressures in two rabbit eyes.

already been pointed out by one of us (Perkins, 1953), and it is intended to pursue this subject in a later paper.

We wish to emphasize again that the results we have obtained and the deductions therefrom apply only to the rabbit eye. However, a recent paper by McDonald (1955) provides clinical evidence suggesting that in the human, eye, "scleral rigidity bears some inverse relationship to the intra-ocular pressure". Our preliminary results on stored human eyes suggest that, although the coefficient of rigidity does not remain constant, the type of variation with intra-ocular pressure is not the same as that found in the rabbit eye.

\section{Summary}

(1) Using methods previously described, the coefficient of ocular rigidity for the enucleated rabbit eye was found not to differ from that for the eye in situ.

(2) Results obtained using a technique in which the eye was cannulated through the optic nerve were substantially the same as those obtained by cannulation of the anterior chamber.

(3) At high intra-ocular pressures $(50-150 \mathrm{~cm}$. saline) the coefficient of rigidity showed less variation than at lower pressures. 
(4) Two methods are described for measuring ocular rigidity in the rabbit eye using a Schiøtz tonometer. Tonometric estimations gave values for the coefficient of rigidity comparable to those obtained by distension of the eye, and these values were also dependent on intra-ocular pressure.

\section{REFERENCES}

Friedenwald, J. S. (1937). Amer. J. Ophthal., 20, 985.

(1954). "Standardization of Tonometers", Decennial Report by the Committee on Standardization of Tonometers. American Academy of Ophthalmology and Otolaryngology.

and Moses, R. (1950). Docum. ophthal., 4, 335.

Gloster, J., Perkins, E. S., and POMmIER, M. L. (1957). British Journal of Ophthalmology, 41, 103.

MacDonald, R. K. (1955). Trans. Canad. ophthal. Soc., 7, 178.

Perkins, E. S., and Gloster, J. (1957). British Journal of Ophthalmology, 41, 93.

RIDLEY, F. (1930). Brit. J. exp. Path., 11, 217.

ROHRSCHNEIDER, W., and KÜCHLE, H. J. (1954). Ophthalmologica (Basel), 128, 369.

Schultén, M. W. voN (1884). v. Graefes Arch. Ophthal., 30 (iii), 1. 